\title{
DOS DÉCADAS DE ESTUDIOS SOBRE EL COMERCIO VALENCIANO EN LA EDAD MODERNA
}

\author{
Por Enrique GIMÉNEZ LÓPEZ
}

Universidad de Alicante

Los estudios sobre el comercio marítimo valenciano han conocido en las dos últimas décadas un considerable auge. El desarrollo de la historiografía valenciana, surgido del magisterio de los profesores Jover, Reglá y Giralt, la ha situado entre las más dinámicas del conjunto español, y ello ha beneficiado, indudablemente los estudios sobre el tráfico mercantil en la Edad Moderna. Intentaré dar cuenta del camino recorrido y qué aspectos se mantienen todavía oscurecidos parcial o totalmente cuando estamos próximos a cumplir el vigésimo aniversario de la publicación del libro del, desgraciadamente desaparecido, profesor Alvaro Castillo "Tráfico marítimo y comercio de importación en Valencia».

El desarrollo del comercio está ligado a una gran variedad de condicionantes, de los que no son ajenas la infraestructura portuaria y caminera. Su incidencia como factor de producción y en el costo de las mercancías es considerable, y el marco geográfico junto a la disponibilidad de recursos, condicionaron el comercio del Reino con el interior peninsular y con el mundo mediterráneo o altántico en el Antiguo Régimen valenciano.

Pese a su importancia la historiografía valenciana es deficitaria en estudios que se dediquen específicamente al problema de la infraestructura portuaria y vial en relación con los intercambios comerciales.

De la red caminera valenciana casi nada sabemos ${ }^{(1)}$. La ruta más importante del Reino seguía siendo la que unía Madrid con Valencia por Albacete, mejorada en tiempos de Carlos III y Carlos IV, y que se bifurcaba sobrepasada Almansa hacia Valencia y Alicante a través del Valle del Vinalopó. El resto de los caminos eran deficientes y en su mayoría de herradura, inadaptados a la difícil orografía.

Esta situación y su negativa influencia en la economía no escapó a los comentarios de algunos valencianos contemporáneos, como el jurisconsulto de Oliva, Tomás Manuel Fernández de Mesa, quien publicó en 1755 una voluminosa 
obra titulada Tratado legal y político de caminos públicos y posadas en la que refiere algunas de sus experiencias valencianas, como el obstáculo que suponía para el tráfico entre Valencia y Barcelona, y entre Valencia, Alicante y Andalucía los barrancos de la Viuda y Algemesí, o los largos y costosos rodeos a que obligaba el difícil paso de las Cabrillas.

La alta incidencia que en el costo suponía la deficiente red de transporte terrestre puede ejemplarizarse en los gastos que generó la operación de Campomanes para abastecer Madrid con trigo mediterráneo en 1765. Las 39.054 fanegas de trigo desembarcadas en una de las fases de la operación en el Grao valenciano supusieron 67.448 rls. de gastos de transporte marítimo entre Marsella y Valencia, mientras que fueron 537.896 rls. los que costó transportarlas desde Valencia al pósito de San Clemente, en Cuenca ${ }^{(3)}$.

Pese a tener que soportar el costo suplementario de transportar a lomos de mulas o, en el mejor de los casos, en carretas los géneros importados o exportados por el Reino de Valencia, el volumen del tráfico terrestre fue suficiente para que surgieran en Valencia y Alicante asociaciones de muleros y carreteros organizadas de manera semejante a la gremial. Pese a ser estas organizaciones muy activas a lo largo del siglo XVIII, sólo conocemos de ellas las referencias que indica David Ringrose ${ }^{(4)}$, pero noticias aisladas y datos dispersos, aunque frecuentes, sí que denotan la existencia de un transporte terrestre en manos de un plantel numeroso de especialistas residentes en las poblaciones situadas junto a los caminos reales. Estos carreteros y arrieros hacían posible el flujo de mercancías e, incluso, las autoridades municipales llegaron a regular ese tráfico; por ejemplo, en 1565 el municipio de Alicante dictó bandos que prohibían entregar carga a los carruajes castellanos cuyos conductores no hubieran transportado hasta la ciudad trigo para el consumo urbano(s).

Todo ese hormigueo de caravanas entre el litoral y el interior es lo que llevó a Braudel a afirmar que ese tráfico, y no Castilla solamente, es lo que ha hecho España, «lo que determina y, si se quiere, lo que traiciona a la economía profunda del país» ${ }^{(6)}$. Sin duda alguna, el papel de Castilla y, sobre todo, de la Corte en el comercio de la periferia, ya ha sido destacado por quienes se han ocupado de conocer el entramado comercial español, pero queda mucho camino por recorrer en el estudio de las relaciones entre Castilla y el litoral valenciano ${ }^{(7)}$.

Por lo que se refiere a la infraestructura portuaria, ésta fue siempre en el Reino de Valencia un gran obstáculo para competir con éxito con los puertos catalanes o con los de Cartagena y Málaga en el sur. Las características del puerto de Alicante, abrigado, con buenos accesos y de considerable amplitud, eran una excepción entre la mediocridad portuaria valenciana, limitada por una costa en la que a los acantilados le suceden playas abiertas y de escaso fondo ${ }^{(8)}$.

Pese a que los proyectos para dotar a los deficientes abrigos costeros de instalaciones que paliaran las circunstancias negativas fueron numerosos, y la cartografía existente en los archivos nacionales y militares es muy abundante ${ }^{(9)}$, es éste un aspecto necesitado de estudios a semajanza de los ya efectuados para Valencia. 
Vinaroz en el norte, no contó con muelle hasta 1875, siendo en la Edad Moderna un abrigo natural cuya actividad dependía de ser punto de salida del cereal y la madera del Maestrazgo. Sagunto y Benicassim eran playas abiertas a las que sólo accedían las pequeñas embarcaciones dedicadas al cabotaje, y Gandía sólo existió como puerto a fines del pasado siglo.

El puerto de Denia es algo mejor conocido, aunque las referencias históricas son las que sirven de introducción a estudios de tipo geográfico ${ }^{(10)}$. Sus problemas eran el escaso calado, agravados por los enterramientos, y la dificultad de acceso, ya que se penetraba en la dársena por un angosto canal que a juicio de Chabás necesitaba de «piloto práctico y bien mirado» ${ }^{(11)}$. Cavanilles lo calificó de "poca capacidad e incómodo por las rocas que casi a flor de agua corren en arco de media legua», y proponía la realización de obras para su mejora, pero el proyecto de Alejo Berlinguero, a fines del siglo XVIII, para construir un muelle no se llevó a cabo.

Los intereses marítimos de la ciudad de Valencia chocaron siempre con la geografía, aunque no con la imaginación de infinidad de proyectistas, algunos de cuyos trabajos son hoy conocidos gracias a las aportaciones de Salvador Albiñana y Telesforo Hernández ${ }^{(12)}$. La opinión expresada por el Barón de Bourgoing a finales del siglo XVIII de que «a Valencia sólo le faltaba un puerto para ser una de las ciudades más prósperas de España», era compartida por muchos valencianos que trataban de superar las deficiencias del Grao, abierto a los vientos de levante, con aterramientos por su proximidad a la desembocadura del río y su costa baja y arenosa. En el siglo XVI existía un rudimentario embarcadero de madera, deteriorado con frecuencia e inservible las más de las veces, y aquellos proyectos que se elaboraron para construir un muelle no fructificaron por las dificultades técnicas que presentaba. Desde fines del siglo XVII se sucedieron las propuestas: hacer navegable el Turia desde su desembocadura hasta la ciudad, y construir en ella los muelles; desviar el cauce del Turia para evitar los aterramientos; y construir un puerto en Cullera utilizando la Albufera como canal de navegación. En todas estas iniciativas se mezclaba el interés setecentista por las obras públicas y el transporte marítimo con las ideas arbitristas del siglo anterior, como sucedía también con los proyectos de hacer navegable el Júcar y remontar su cauce con barcazas hasta Castilla, potenciando el comercio interior.

Las noticias que hasta hace poco poseíamos de Alicante, el principal puerto del Reino, eran escasas. Julia López Gómez ofreció algunos datos aislados y yo mismo sólo mencioné las modificaciones y reformas realizadas durante el siglo XVIII en su muelle, que ya era de piedra a fines de la Edad Media, y una somera referencia a los proyectos de 1749,1772 y 1800 . La reciente publicación de Guillermina Subirá «Evolución histórica del puerto de Alicante» ofrece una más extensa información sobre éstos y otros proyectos, la aportación municipal a la mejora portuaria en los siglos XVI y XVII, y otras noticias sobre la cartografía y la imbricación de lo comercial y lo militar ${ }^{(13)}$.

Las fuentes determinan en muchos casos el alcance de la investigación. Para 
la época foral el Archivo del Reino conserva una abundantísima documentación relativa al comercio que sólo en parte ha sido utilizada y que es, sin duda, la más completa de las conservadas en las ciudades mediterráneas junto a la de Livorno ${ }^{(14)}$.

Los libros del Peaje del Mar, impuesto que gravaba las mercancías que entraban y salían del Reino de Valencia, han servido para conocer la evolución y tipología de las importaciones de la capital del Reino en el siglo XVI ${ }^{(15)}$, y en los primeros veinte años del siglo XVII ${ }^{(16)}$. Lógicamente queda mucho por hacer, sobre todo en lo relativo a Alicante, de cuyo comercio nada sabemos pese a su relevancia portuaria. La documentación denominada Quema ${ }^{(17)}$, que afectaba al comercio con Castilla, conserva muchos libros referentes a la primera mitad del siglo XVII y de la última década de ese mismo siglo referentes a Alicante, y Xátiva cuenta también con información interesante e inexplorada. Los libros denominados de la Desclauquillá, cuya función administrativa era el control de ciertas mercancías, pese a su gran valor no han sido utilizados por las lagunas que ofrecen, pero de ellos es posible obtener informaciones muy precisas sobre el lugar de origen de los géneros procedentes no sólo del exterior del Reino, sino los elaborados en otras poblaciones valencianas.

Gracias a los trabajos de Emilia Salvador y Alvaro Castillo, es posible fijar la evolución del tráfico de importación de la ciudad de Valencia durante la época foral. La primera mitad del siglo XVI conoció una moderada tendencia al alza, no interrumpida por el conflicto agermanado. Sólo la inseguridad que provocaban los ataques berberiscos suponía un motivo de inestablidad a un comercio vinculado casi exclusivamente al ámbito mediterráneo occidental.

Hacia mediados del siglo, el comercio valenciano pasó por una crisis profunda que contrajo los contactos comerciales a sólo las regiones vecinas de Cataluña y Mallorca. Esta situación comenzó a superarse hacia 1565, año en el que se inició una fuerte expansión que duplicó en escaso tiempo el número de embarcaciones, pasando éstas de 500 en 1576 a 1.000 en 1605, y ampliándose el marco de las relaciones comerciales. En esos años Valencia amplió sus contactos comerciales al Mediterráneo oriental y al Atlántico, con una creciente presencia inglesa y holandesa en el mar interior.

Esta situación de auge comercial se vio interrumpida bruscamente en 1605, año en que se inició un fuerte descenso en el número de embarcaciones llegadas al Grao, pese a la todavía notable presencia de navíos procedentes del Atlántico.

Esta coyuntura negativa cambió de signo hacia 1635 , pese a que en ese año España y Francia iniciaron su confrontación bélica que finalizaría en 1659 con la Paz de los Pirineos. La guerra no interrumpió las relaciones comerciales entre Valencia y los puertos franceses, entre los que descollaba Marsella, y el Reino se vio favorecido por la crisis de la Monarquía de 1640 que provocó el colapso del comercio del Principado y el consiguiente beneficio para Valencia ${ }^{(18)}$.

Estos análisis de la coyuntura, si bien necesarios e interesantes, sólo constituyen un capítulo del comercio valenciano en la época foral ya que describen la 
trayectoria del comercio marítimo de importación, pero es necesario vincular ese tráfico con el consumo, los precios, los salarios y la producción.

Es esa una temática todavía no abordada y repleta de dificultades. No lo es tanto, sin embargo, conocer con detalle la incidencia en la economía valenciana de ciertos productos clave en la estructura de las importaciones, como los textiles y el pescado salado, y esperemos que la publicación del trabajo del norteamericano Richard Ling ${ }^{(19)}$ arroje luz sobre esta dimensión del comercio valenciano y su evolución en el tiempo. En él se estudian desde la fuerte presencia de lienzos baratos franceses en la primera mitad del siglo XVI, hasta la penetración de telas inglesas y flamencas a partir de 1560 , o el no menos importante comercio de salazones, uno de los escasos productos que posibilitaron el contacto de los valencianos de reducidos recursos con las economías extraregionales. El interés por este comercio del pescado salado no es sólo por ser uno de los más voluminosos del tráfico comercial, sino que permite, además, conocer el funcionamiento de un mercado de productos de consumo popular en los siglos XVI y XVII.

Pese a su importancia muy poco sabemos del papel jugado por el litoral valenciano en la exportación de lanas castellanas. Quizá se deba esta carencia a que los historiadores valencianos no han utilizado los fondos documentales del Tribunal Mayor de Cuentas conservados en el Archivo General de Simancas y relativos al Derecho Nuevo y Derecho Antiguo, tributos que gravaban la exportación de lana por los puertos castellanos y por los de la Corona de Aragón. Los resultados obtenidos por Jonathan I. Israel en su trabajo «Spanish wool exports and the european economy, $1610-1640 \gg{ }^{(20)}$, permiten vislumbrar lo fructífero y necesario que resulta situar al comercio valenciano en el contexto del comercio internacional y, como indicó $\mathrm{H}$. Lapeyre ${ }^{(21)}$, el peso en ocasiones determinante de la gran política en el tráfico comercial. Ciertamente, la sublevación de los Países Bajos en los años sesenta desvió una importante parte de la exportación lanera del Atlántico hacia Alicante, puerto por el que salía lana hacia Francia e Italia. Asimismo el deterioro de la relaciones franco-españolas durante las Guerras de Religión convirtieron al puerto alicantino en uno de los principales puntos exportadores de lana a fines del siglo XVI, para más tarde perder ese importante rol como consecuencia del fin de la Tregua de los Doce Años en 1621 y el comienzo de la guerra comercial declarada por Olivares a las Provincias Unidas ${ }^{(22)}$.

Pese a estas lagunas, zonas mejor iluminadas o atisbos que señalan importantes aspectos del comercio valenciano en la época foral, se encuentran en las dos últimas décadas del siglo XVII, las mejor conocidas. Desde que Hamilton (23), Reglá y Sebastián García Martínez después ${ }^{(24)}$, señalaran el simbólico año 1680 como punto de arranque de la recuperación económica valenciana, la etapa inmediatamente anterior al conflicto sucesorio ha merecido por los historiadores una creciente atención. Ya que el comercio se comporta como un importante indicador de la actividad productiva, se detectan señales de vitalidad: aumento del tráfico, solicitud de puerto franco para Valencia en 1679, y la creación en 1692 de la Junta de Comercio con la intención de canalizar la favorable situación de 
la economía valenciana en las directrices mercantiles de la monarquía de Carlos II ${ }^{(25)}$. Por entonces se iniciaron, aunque sin la intensidad de la segunda mitad del siglo XVIII, los roces entre Alicante y Valencia a causa de quién debía ostentar en el Reino la preeminencia comercial.

La tímida política mercantilista ensayada en los últimos años del siglo XVII tenía escasas posibilidades de prosperar en Valencia. Valencia necesitada de la importación de cereales para su consumo, con elevadas entradas de pescado salado y géneros manufacturados, sólo podía corresponder mediante la exportación de frutos secos, sal, vino, sosa y, sobre todo, seda en crudo. A pesar de las medidas destinadas a evitar la exportación de la seda valenciana, la estructura de los intercambios hizo baldío cualquier intento proteccionista que, por otro lado, tampoco encontró valedores en las más altas instancias de la administración valenciana. El propio Virrey afirmaba que la exportación sedera era un «universal beneficio» $\mathrm{y}$ «principal y única cosecha» que posibilitaba el pago de las importaciones trigueras ${ }^{(26)}$.

Para Henry Kamen esa balanza comercial deficitaria para Valencia sólo era compensada por una eficaz organización mercantil, que el historiador británico ejemplifica a través de la trayectoria comercial del mercader alicantino Felipe Moscoso, cuya descripción, basada en su correspondencia de los años 1660-1681, constituye una de las escasas referencias a quienes protagonizaron la actividad comercial valenciana en la época foral ${ }^{(27)}$, junto al apunte dedicado por Carlos Martínez Shaw a la organización de la ruta comercial entre Lisboa y el Reino de Valencia para la importación de productos coloniales, articulada en torno al triángulo formado por los puertos de Valencia, Denia y Alicante ${ }^{(28)}$. En este último trabajo queda patente, una vez más, que las exportaciones valencianas a Lisboa fundadas en el vino, el aguardiente, las pasas y el arroz, suponían un valor algo menor de la mitad del precio de los productos coloniales importados.

Los estudios sobre el comercio valenciano en el siglo XVIII son, todavía hoy, insuficientes. Las causas que lo motivan pueden deberse a que la amplia implantación del régimen señorial en tierras valencianas ha estimulado a los historiadores a buscar en el sector agrario setecentista las razones que mejor pueden explicar la desindustrialización valenciana en el siglo XIX. La tesis de Emili Giralt era que el proceso desamortizador iniciado por la Revolución liberal había absorbido los capítulos de procedencia agraria acumulados durante la expansión del siglo anterior ${ }^{(29)}$, mientras que la debilidad de la burguesía, reducida su fuerza por el triunfo de los intereses señoriales tras la contienda sucesoria, había contribuido poderosamente a ello ${ }^{(30)}$.

Esa supuesta debilidad de la burguesía valenciana y la omnipresencia del mundo rural, condujeron a los historiadores a fijar su atención en el mundo agrario ${ }^{(31)}$, relegando al comercio a una zona de sombras que está consiguiéndose iluminar con los trabajos efectuados en los últimos años referentes a los mercados exteriores y al mercado interior, la estructura técnica de comercio, su estructura social, las instituciones y la incidencia del comercio americano. 
El tráfico portuario valenciano del siglo XVIII sólo es conocido en lo relativo a Alicante en la segunda mitad del siglo XVIII, y para Valencia en los últimos años de este siglo y primeros del siglo XIX. La posibilidad de contar con los registros de las embarcaciones admitidas a comercio, denominados «mesadas de sanidad», nos ha posibilitado conocer el volumen y tipología del tráfico entre los años 1753 y 1805 a través de las 54.208 unidades de alto bordo y cabotaje ${ }^{(32)}$. El profesor José Miguel Palop, utilizando los «registros de embarcos y desembarcos en el puerto de Valencia» ha logrado reconstruir los rasgos básicos del comercio marítimo del Grao en el período final de siglo ${ }^{(33)}$, y él mismo con anterioridad había marcado la evolución del tráfico portuario valenciano a través de las series municipales de la renta conocida como "aduanas del mar», por la que el ayuntamiento valenciano ingresaba la mitad del gravamen del $15 \%$ cobrados por la Real Hacienda en la Aduana de Valencia. La evolución de la serie coincide con la trayectoria del movimiento portuario alicantino ${ }^{(34)}$, y en ambos casos las distorsiones se producen como consecuencia de la aparición de algún foco epidémico en el Mediterráneo o por el inicio de un conflicto armado.

Ciertamente las contracciones del tráfico se deben no a fenómenos estrictamente económicos, sino a situaciones que inciden en la economía, como las medidas cautelares tomadas para evitar las epidemias, o la entrada en guerra de España y otras potencias marítimas europeas. La gran epidemia de peste de Marsella de 1720, la última sufrida por la Europa occidental, colocó bajo mínimos al comercio valenciano ${ }^{(35)}$, y si no con la misma incidencia, el tráfico se redujo a consecuencia de los focos epidémicos que frecuentemente eran detectados en el norte de África ${ }^{(36)}$. La epidemia de fiebre amarilla declarada en Alicante en 1804 supuso la paralización del tráfico al ordenar las autoridades cerrar al comercio dicho puerto.

Pero eran las guerras las que indudablemente tenían un efecto más negativo sobre el comercio. En Alicante las fases regresivas coinciden con la Guerra de los Siete Años o con el inicio del ciclo bélico que enfrenta a Francia con Inglaterra en los años setenta con motivo de la guerra de la independencia norteamericana, en la que posteriormente intervino España. El rígido paralelismo entre actividad marítima y situación bélica se agravó con el inicio del largo ciclo bélico en 1793, que al coincidir con las crisis agrarias de fines de siglo, supuso una situación de desabastecimiento muy preocupante.

Las relaciones mercantiles valencianas en el siglo XVIII, si bien siguen siendo dominadas por el tráfico mediterráneo, mantienen crecientes contactos con el mundo atlántico. Las escasas noticias que poseemos sobre el Grao valenciano indican que su comercio giraba en torno a Marsella, Génova y Amsterdam, importantes centros de redistribución de productos de diversas procedencias, y los datos que Matilde Alonso elaboró para 1790 sobre los fondos consulares depositados en los Archivos Nationales de París confirman la importancia de Marsella en el comercio valenciano, pues es de la capital de la Provenza de donde proceden la mitad de las embarcaciones de pabellón francés llegadas a las costas valencia- 
nas, y el $55 \%$ de las que parten tienen aquel destino ${ }^{(37)}$. Más precisa es la información que poseemos de Alicante, y conviene referirse a los contactos de su comercio uniéndolo a los productos importados.

Sin duda en el cereal el producto de importación más importante en volumen de los desembarcados en el antiguo Reino, ya que su introducción en el país era imprescindible para suavizar las crisis trigueras, puesto que el campo valenciano tan sólo producía para cubrir unos pocos meses posteriores a la cosecha. La base de las importaciones trigueras era Sicilia, Cerdeña y La Apulia, transportándose generalmente en buques británicos y holandeses, y otros puntos del litoral mediterráneo francés, pero también obtiene importancia el arribo del embarciones con trigo procedente de los puertos del Canal e, incluso, de Norteamérica pues tras la independencia navíos de pabellón estadounidenses llegan a Alicante transportando harina.

El segundo gran producto alimenticio de importación era, prosiguiendo la situación del siglo anterior, el pescado salado procedente, mayoritariamente, de las pesquerías de Terranova y conducido por navías ingleses. Como prueba evidente de su importancia téngase en cuenta que más de 1.200 embarcaciones inglesas desembarcaron bacalao en Alicante en la segunda mitad del siglo XVIII, sobre todo en los meses de otoño e invierno de cada año, fechas habituales en la llegada de los cargamentos de bacalao. La sardina salada, era, sin embargo, un cuasi monopolio catalán, quienes la transportaban desde sus factorías andaluzas y gallegas.

Cádiz era el puerto redistribuidor de productos coloniales muy particularmente azúcar y cacao, que llegaba hasta los puertos valencianos transportado por un enjambre de pequeñas embarcaciones de cabotaje, y puerto emisor de los escasos productos valencianos destinados a América.

Los productos manufacturados era un importante capítulo en las importaciones valencianas. Marsella y Génova, salidas naturales al mar de las manufacturas del sur de Alemania y norte de Italia, son los principales lugares de donde procede la pañería, lencería, objetos metálicos, quincallería, papel, etc. Inglaterra, Holanda y los países escandinavos también se hallan presentes en el comercio valenciano de importación, pero su importancia es menor.

Sobre las exportaciones las noticias que poseemos son aún muy fragmentarias, aunque suficientes para mostrar la debilidad exportadora valenciana. Los datos menejados por Palop Ramos ${ }^{(38)}$ para Valencia constatan el predominio de las materias primas textiles, seguidas por el vino y el aguardiente. Sólo se encuentran tejidos de seda y algunas partidas de azulejos entre los escasos productos manufacturados de origen valenciano.

En Alicante la barrilla suponía uno de los principales capítulos exportadores, ya que aquel puerto contaba con la condición de punto de embarque exclusivo de la sosa y la barrilla, materias primas muy estimadas en Europa por su utilización en vidrio y jabón ${ }^{(39)}$. Seguían en importancia los frutos secos, el vino, las fibras textiles semielaboradas o en bruto. Marsella, como ya indicamos, era el 
principal destino de los productos exportados, seguido de Génova, pero con una presencia cada vez mayor de puertos atlánticos receptores de sosa, espartería, pasas, vino, etc., destacando los de Plymouth y Londres, con crecientes importaciones de frutos secos, y los de Amsterdam, Ostende, El Havre o Estocolmo, entre otros ${ }^{(40)}$.

Sobre la estructura técnica del comercio valenciano, incluyendo en ella tanto el estudio de los instrumentos como de las técnicas del comercio, se ha producido un significativo avance gracias a la publicación de una parte de la tesis doctoral de Ricardo Franch ${ }^{(41)}$, una de las oportaciones más interesantes sobre el comercio valenciano de los últimos años, y que avanza en el camino emprendido por Vicente Ribes en un libro anterior ${ }^{(42)}$.

Gracias al trabajo de Franch, algunas de cuyas conclusiones habían sido avanzadas durante el II Coloquio de Metodología Aplicada ${ }^{(43)}$, sabemos que las compañías comerciales de la ciudad de Valencia tenían un carácter familiar, con socios habitualmente ligados por lazos de parentesco, y con una duración que habitualmente no superaba el cuatrienio. Otra de sus sugerentes conclusiones, como la de valorar la importancia del tráfico de importación de la ciudad de Valencia a través de la contribución de aduanas y del derecho consular, situándolo a niveles semejantes, sino superiores, al comercio de importación alicantino, deben tomarse con reserva hasta que documentación más fiable que la puramente fiscal ratifique una afirmación contraria a testimonios contemporáneos de muy diversa indole.

Vicente Ribes ha descrito el sistema mercantil practicado por las compañías valencianas vinculadas a la exportación de tejidos de seda a América. El proceso se iniciaba con la adquisición de la cosecha de seda en localidades de la Ribera del Júcar, seda que posteriormente era elaborada por los artesanos del Colegio Mayor y enviada a Cádiz utilizando arrieros o embarcaciones de cabotaje. Ya en Cádiz eran los corresponsales de estas compañías los encargados de su venta, seguro y embarque, redactando informes sobre la situación del mercado americano para adecuar la oferta a la demanda colonial.

El seguro marítimo, los fletes, el papel de la letra de cambio o el crédito comercial son, todavía, parcelas de las que casi nada conocemos, aunque conviene señalar que los trabajos sobre el comercio español carecen de este tipo de estu$\operatorname{dios}{ }^{(44)}$.

De la estructura social del comercio valenciano sabemos algo más. La fuerte presencia de comerciantes extranjeros ha sido valorada como una prueba de la debilidad de la burguesía mercantil autóctona. En 1767 el Administrador General de Rentas informó a la Junta de Comercio que de las sesenta y dos casas de comercio dedicadas al por mayor instaladas en la ciudad, treinta y cinco eran extranjeras, en su mayoría francesas. En Valencia el número de comerciantes extranjeros era también numeroso, sobre todo bearneses y genoveses ${ }^{(45)}$. Los casos particulares mejor conocidos muestran una cierta tendencia a la integración. En el trabajo de R. Franch sobre la evolución de tres importantes dinastías comerciales genovesas se analiza ese proceso de asimilación a través de la adquisición 
de bienes inmuebles y de los enlaces matrimonial ${ }^{(46)}$; yo mismo he estudiado parecido comportamiento a través de la peripecia personal de la familia bretona de los Marabeuf, enriquecida con el comercio, inversora en propiedades rústicas y urbanas, ennoblecida en 1740 y arruinada a fines de siglo ${ }^{(47)}$. Manuel Ardit ha descrito casos de inversiones de destacados miembros del comercio valenciano en propiedades agrícolas y su posterior ennoblecimiento ${ }^{(48)}$, y el profesor Molas Ribalta ha señalado la escasa vinculación de ésta inmadura burguesía valenciana a una manufactura muy apegada a formas artesanales y corporativas, lo que dirigió prioritariamente las inversiones de capital comercial hacia la agricultura y a verse atraida fuertemente por el ennoblecimiento ${ }^{(49)}$.

Cuantificar la inversiones de la burguesía mercantil aparece como una urgente tarea a realizar, ya que una vez demostrada por R. Franch la importancia de la acumulación de capitales de origen mercantil, es imprescindible conocer el nivel de repatriación de los beneficios por comerciantes que regresan a sus países de origen o por comerciantes nacionales que actúan como simples comisionistas de casas extranjeras, las inversiones en bienes urbanos y rústicos y, por último, la inversión en mercancías y crédito.

Los estudios sobre organismos o instituciones encargadas de regir o regular aspectos del comercio valenciano en el siglo XVIII son más abundantes. En Valencia, siguiendo el modelo de la Junta de Comercio de Barcelona, se erigió entre 1762 y 1765 la de aquella ciudad, institución que pretendía recoger la tradición del Consolat medieval e impulsar al tiempo, el fomento de la agricultura y las manufacturas del Reino mediante la incorporación de hacendados y artesanos notables. Pere Molas Ribalta, utilizando la rica información recopilada por Eugenio Larruga ${ }^{(50)}$, ha estudiado la evolución de la Junta de Comercio valenciana y la fuerte oposición que encontró en la colonia mercantil extranjera, en la Real Audiencia, opuesta a la autonomía del Consulado en la jurisdicción mercantil, y en la ciudad de Alicante, quien se negó abierțmente a reçonocer la autoridad de la Junta ${ }^{(51)}$.

La disputa entre Valencia y Alicante por la cuestión del Consulado es un capítulo más de las rivalidades que han jalonado las relaciones entre las dos principales ciudades de la comunidad, y una muestra de las muchas que podríamos sacar aquí a colación para tratar del fuerte sociocentrismo valenciano y el efecto de esta heterogeneidad en la fragmentación política valenciana.

La importante presencia de comerciantes extranjeros en el comercio alicantino fue una de los elementos argumentales de la disputa, aunque en el fondo se trataba de tensiones derivadas de la creciente rivalidad entre ambas ciudades, la una capital histórica del Reino, la otra ciudad en expansión y centro comercial importante.

Los avatares del pleito son, en líneas generales, conocidos ${ }^{(52)}$ : en 1775 se creó una Diputación Consular de Valencia en Alicante con la precaución de poner a su frente a un comerciante alicantino provalenciano y desvinculado de las casas comerciales extranjeras y del comercio de salazones; en 1785, finalmente, se creó en Alicante un Consulado de comercio propio ${ }^{(53)}$. 
La Real Sociedad Económica de Amigos del País de Valencia creada en 1776, realizó escasas actividades relacionadas con el comercio, y las que intentó se saldaron con poco éxito, como la convocatoria durante varios años de un premio a la mejor memoria sobre el modo de fomentar la marina mercante valenciana y que siempre se declaró desierto ${ }^{(54)}$.

Queda, para finalizar, una obligada referencia a la participación valenciana en el comercio colonial, por razón de proximidad al V Centenario del Descubrimiento y por la aparición, en los últimos tiempos, de trabajos que inciden en un sector del que casi no sabíamos nada hasta hace bien poco.

El libro de Vicent Ribes «Los valencianos y América» (55) ha supuesto un esfuerzo por conocer el comercio valenciano con el Nuevo Mundo vía Cádiz, o directamente tras el decreto de libertad de comercio de 1778 . Ribes valora positivamente las relaciones con la gran plaza gaditana, vital en la exportación de tejidos de seda y papel, y achaca a la rivalidad entre Valencia y Alicante la escasa participación en el comercio directo con América. Ciertamente la demanda americana influyó en la producción valenciana de tejidos de seda y papel, pero debemos ser prudentes al valorar su impacto. Los trabajos publicados por Manuel Ardit sobre la Compañía de comercio de Mariano Canet ${ }^{(56)}$, muestran la cautela de este comerciante en la relativo al comercio americano y la consiguiente modestia de los capitales aventurados en estas empresas. La escasamente airosa posición que Alicante, único puerto valenciano habilitado, tuvo en el comercio directo, no sólo es consecuencia de un hipotético boicot de los comerciantes de la ciudad de Valencia, como indica Ribes, sino, sobre todo, un reflejo de la propia debilidad de la burguesía mercantil autóctona, de la fuerte presencia del comercio extranjero y la consiguiente situación de dependencia que pesó sobre el desarrollo valenciano en los siglos XIX y XX. 


\section{NOTAS}

(1) Vénase las posibilidades que tiene su estudio en el capítulo introductorio de Josep M. BERNABÉ MAESTRE: Industria i subdesenvolupament, Mallorca 1975.

(2) Un estudio sobre Fernández de Mesa en Santos MADRAZO MADRAZO: "Tres arbitristas camineros de mediados del siglo XVIII», Hispania, n. ${ }^{\circ} 126$, pp. 169-193.

(3) José Miguel PALOP: «El litoral valenciano y al avituallamiento triguero de Madrid. Hambres de 1754 y $1766 »$ en Estudis, n. ${ }^{\circ} 5$ (1976), pp. 125-155.

(4) David RINGROSE: Los transportes y el estancamiento económico de España, Madrid 1972, p. 121 .

(5) A. M. A. Privilegios y provisiones reales, Arm. I, Lib. 12, f. 80.

(6) Fernand BRAUDEL: El Mediterráneo y el mundo mediterráneo en tiempos de Felipe II, Madrid 1976, vol. I, pp. 68-9.

(7) David RINGROSE: Madrid y la economía española, 1560-1850, Madrid 1985; M. ${ }^{a}$ Carmen GARCÍA MONERRIS Y J. L. PESET: «Los gremios menores y el abastecimiento de Madrid durante la Ilustración», Moneda y Crédito, $\mathrm{n} .{ }^{\circ} 140$ (1977), pp. 67-97.

(8) Vicens ROSSELLÓ: El litoral valenciá, Valencia 1969, 2 vls.

(9) I. VALLÉS: Cartografía histórica valenciana, Valencia 1979; Horacio CAPEL y otros: Los ingenieros militares en España. Siglo XVIII, Barcelona 1983.

(10) José COSTA MAS: El Marquesat de Denia, Valencia 1978, pp. 561-563; Matilde RUIZ GALLEGO: «El puerto de Denia», en Cuaderno de Geografía n. ${ }^{\circ}$ 4, Valencia 1967, pp. 235-267.

(11) Roque CHABAS: Historia de Denia, Alicante 1986 (sobre la edición de 1874), p. 51.

(12) S. ALBIÑANA Y T. HERNÁNDEZ: «Técnica e Ilustración en Valencia, los proyectos portuarios», en Saitabi, XXXIV (1984), pp. 12 -151. Ibid: «Los novatores ante la problemática portuaria de Valencia en el S. XVII», en Estudios dedicados a Juan Peset Aleixandre, Valencia 1982, II, pp. 353-374. Aunque el tema no es el portuario también conviene manejar el artículo de ambos autores «Notas sobre técnica y proyectismo en la Albufera y el Júcar en la Edad Moderna» en Estudis n. ${ }^{\circ} 10(198)$, pp. 55-90, por las referencias a los proyectos de canalización.

(13) Julia LÓPEZ GÓMEZ: «El puerto de Alicante», en Estudios Geográficos, n. ${ }^{\circ}$ 60, XVI (1955), pp. 511-583; Enrique GIMÉNEZ LÓPEZ: Alicante en el siglo XVIII. Economia de una ciudad portuaria a fines del Antiguo Régimen. Valencia 1981, pp. 25-27; Guillermina SUBIRA JORDANA: Evolución histórica del puerto de Alicante. Alicante 1987, pp. 27-151.

(14) Emilia SALVADOR ESTEBAN: «Las fuentes fiscales valencianas en la Edad Moderna: naturaleza y aprovechamiento", en Actas de las II Jornadas de Metodología Aplicada. Historia Moderna. Cáceres 1983, pp. 125-145; Ives AUFFRAY y J. GUIRAL: «Les peages du Royaume de Valence (1494)», en Melanges de la Casa de Velázquez, XII (1976), pp. 141-163.

(15) Emilia SALVADOR ESTEBAN: La economía valenciana en el siglo XVI. Comercio de importación. Valencia 1972.

(16) Alvaro CASTILLO PINTADO: Tráfico maritimo y comercio de importación en Valencia. Madrid 1967. 
(17) Teresa CANET APARISI: «Los orígenes medievales de un impuesto moderno: la "Quema", en Revista de Historia Moderna. Anales de la Universidad de Alicante, n. ${ }^{\circ} 3,1983$, pp. 181-190.

(18) Alvaro CASTILLO PINTADO: «La coyuntura de la economia valenciana en los siglos XVI y XVII", en Anuario de Historia Económica y Social, II, (1969), pp. 239-288. Vid. también Leonor MALDONADO IZQUIERDO: «Un ejemplo del comercio valenciano en el siglo XVII. La importación marítima en el año 1650», en Anales de la Universidad de Alicante. Escuela de Magisterio n. ${ }^{\circ} 3$ (1986), pp. 153-160.

(19) Richard LING: Long-Term movements in the Trade of Valence, Alicante and the Western Mediterranean 1450-1700, próximo a publicarse por el Instituto de Estudios Juan Gil-Albert, de la Diputación Provincial de Alicante.

(20) Jonathan I. ISRAEL: «Spanish wool exports and the European Economy, 1610-1640», en The Economic History Review, 2. ${ }^{\mathrm{a}}$ serie, XXXIII, n. ${ }^{\circ}$ 2, mayo 1980.

(21) Henry LAPEYRE: «Le commerce des laines en Espagne sous Philippe II» en Bulletin de la Societé d'histoire moderne $\mathrm{n} .^{\circ} 14,1955$.

(22) Jonathan I. ISRAEL: «Un conflicto entre imperios: España y los Países Bajos, 1618-1648», en Poder y Sociedad en la España de los Austrias, Barcelona, pp. 145-197.

(23) Earl J. HAMILTON: War and prices in Spain, 1651-1800, Cambridge, Mass., 1947, pp. 118-137.

(24) Sebebastińa GARCÍA MARTÍNEZ: Els fonaments del Pais Valencia Modern, VAlencia 1968.

(25) Pedro MOLAS RIBALTA: “Valencia y la Junta de Comercio» en Estudis, n. 3 (1975), pp. 55-111.

(26) Pere MOLAS RIBALTA: Comerc y estructura social a Catalunya i Valencia al segle XVII i XVIII, Barcelona 1977, pp. 47-69.

(27) Henry KAMEN: La España de Carlos II, Barcelona 1981, pp. 219-226.

(28) Carlos MARTÍNEZ SHAW: «Algunos aspectos del comercio valenciano con Lisboa a fines del siglo XVIII» en Primer Congreso de Historia del Pais Valenciano, III, Valencia 197 , pp. 473-489.

(29) Emilio GIRALT: «Problemas históricos de la industrialización valenciana», en Estudios Geográficos, n. ${ }^{\circ} 112-113$ (1968), pp. 369-395.

(30) Mario GARCÍA BONAFÉ: «El marco histórico de la industrialización valenciana», en Información Comercial Española, n. ${ }^{\circ} 485$ (1974), pp. 135-146.

(31) Ernest LLUCH afirmaba que «la raó pot venir del fet que e pes del règim senyorial valencià era tan important que aixafà la possibilitat de la consolidació d'un capitalisme comercial autòcton», en La via valenciana, Valencia 1976, p. 122.

(32) Enrique GIMÉNEZ LÓPEZ: Op. cit., pp. 337-354.

(33) José Miguel PALOP RAMOS: «La estructura del tráfico comercial marítimo de Valencia a fines del siglo XVIII. Aproximación a su estudio», en Mayans y la Ilustración, Valencia 1981, II, pp. 697-727.

(34) José Miguel PALOP RAMOS: Hambre y lucha antifeudal. La crisis de subsistencias en Valencia (siglo XVIII), Madrid 1977, p. 40 y 226-227.

(35) Mariano PESET y Pilar MANCEBO: «Temores y defensa de España frente a la peste de MarsellA DE 1720», en Asclepio, XXIII (1971), pp. 131-189; y Enrique GIMÉNEZ LÓPEZ: «Alicante y la peste de Marsella de 1720» en Canelobre, n. ${ }^{\circ} 4$ (1985), pp. 98-104.

(36) José Miguel PALOP RAMOS: Hambre y lucha..., pp. 44-47. Focos epidémicos en 1726, 1728 y 1734 .

(37) Matilde ALONSO PÉREZ: «Un estudio de aplicación de las técnicas informáticas a la investigación histórica. El comercio mediterráneo franco-español a fines del siglo XVIII», Revista de Historia Moderna. Anales de la Universidad de Alicante, n. ${ }^{\circ} 3$ (1983), pp. 115-137. 
(38) J. M. PALOP RAMOS: «La estructura del tráfico comercial marítimo de Valencia a fines del siglo XVIII. Aproximación a su estudio» en Mayans y la Ilustración, II, Valencia 1981, pp. 697-727.

(39) Enrique GIMÉNEZ LÓPEZ: «Auge y ocaso de las plantas barrilleras en el Mediterráneo español» en Canelobre n. ${ }^{\circ} 5,1985$, pp. 51-56.

(40) Ibid.: Alicante en el siglo XVIII..., pp. 390-399.

(41) Ricardo FRANCH BENAVENT: Crecimiento comercial y enriquecimiento burgués en la Valencia del siglo $X$ VIII. Valencia 1986.

(42) Vicente RIBES: Los valencianos y América. El comercio valenciano con Indias en el siglo $X$ VIII. Valencia 1985.

(43) Ricardo FRANCH: «Dinastías comerciales genovesas en la Valencia del s. XVIII: los Causa, Batifora y Ferrano" en La documentación notarial y la Historia, II, Santiago 1984, pp. 295-315.

(44) Antonio-Miguel BERNAL y Antonio GARCIA-BAQUERO: Tres siglos de comercio sevillano (1598-1868). Cuestiones y problemas. Sevilla 1976.

(45) José Miguel PALOP RAMOS: Fluctuaciones de precios y abastecimiento en la Valencia del siglo XVIII, Valencia 19 .

(46) Ricardo FRANCH: «Dinastías comerciales...»

(47) Enrique GIMÉNEZ LÓPEZ: «La burguesía mercantil y la propiedad en el s. XVIII. El caso de Alicante» en La Ilustración Española, Alicante 1986, pp. 477-496.

(48) Manuel ARDIT LUCAS: Revolución liberal y revuelta campesina, Barcelona 1977, pp. 62-66.

(49) Pedro MOLAS RIBALTA: La burguesía mercantil en la España del Antiguo Régimen, Madrid 1985, pp. 209-237.

(50) Eugenio LARRUGA: Historia de la Real y General Junta de Comercio, Mss. conservado en el Archivo del Ministerio de Hacienda.

(51) Pere MOLAS RIBALTA: Comerç i estructura social..., pp. 306-380.

(52) Enrique GIMÉNEZ LÓPEZ: Alicante en el siglo XVIII., pp. 237-255.

(53) Francisco FIGUERAS PACHECO: El Consulado de Alicante, Alicante 1957, y la más reciente de LUIS MAS Y GIL: Antiguas instituciones económicas alicantinas, 19 , pp. 91-101.

(54) Sobre la Sociedad, vid. Francisca ALEIXANDRE TENA: La Real Sociedad Económica de Amigos del País de Valencia, Valencia 1983.

(55) Vicente RIBES: Los valencianos y América. El comercio valenciano con Indias en el siglo $X V I I I$, Valencia 1985.

(56) Manuel ARDIT LUCAS: «Datos sobre el comercio español con América en el siglo XVIII. Las empresas comerciales de Mariano Canet y Montalbán (1758-1785)» en Estudios dedicados Juan Peset Aleixandre, Valencia 1982, I, pp. 157-174 y «Las empresas comerciales de la Sociedad "Viuda de Don Mariano Canet e Hijos"' y las primeras expediciones directas de Valencia a Veracruz» en E.studis, n. ${ }^{\circ} 11,1985$, pp. 103-142. 